Int. J. Morphol.,

33(2):452-458, 2015

\title{
An Osteometric Evaluation of the Foramen Spinosum and Venosum
}

\author{
Una Evaluación Osteométrica de los Forámenes Espinoso y Venoso
}

\author{
L. Lazarus*; N. Naidoo* \& Satyapal, K. S."
}

LAZARUS, L.; NAIDOO, N. \& SATYAPAL, K. S. An osteometric evaluation of the foramen spinosum and venosum. Int. J. Morphol., 33(2):452-458, 2015

SUMMARY: The foramen spinosum (FS) and foramen venosum (of Vesalius) (FV) are alisphenoid apertures situated within the hub of the middle cranial fossa in close proximity to foramen ovale (FO). The FS and FV provide a passage to important neurovascular structures. An accurate knowledge of the morphometric details of the FS and FV including their shape, incidence, relation to other foramina and/or presence of any anomalies may represent a reliable anatomical landmark during surgical explorative maneuvers. Therefore, the aim of this study was to investigate the morphologic and morphometric features of the FS and FV. The study was conducted on 100 dry human skulls $(n=200)$ obtained from the osteological bank at the University of KwaZulu-Natal, to produce a database which may serve as a useful guideline to surgeons and anesthetists. Although single $(95 \%)$, duplicate $(2.5 \%)$ and triplicate $(0.5 \%)$ FS were identified; only single (5\%) and duplicate $(0.5 \%) \mathrm{FV}$ were found. Oval (FS: $43.5 \%$; FV: $4.5 \%$ ) and round (FS: $58 \%$; FV: $0.5 \%)$ foramina were observed. In addition, the relationship of the FS and FV to FO was recorded: postero-lateral (FS: 93\%; FV: 0\%); posterior (FS: 1.9\%; FV: 0\%); postero-medial (FS: 0.5\%; FV: 0\%); anterior (FS: 0\%; FV: 0.5\%); antero-medial (FS: 0\%; FV: 4.5\%). The mean morphometric parameters of the FS and FV included the internal diameter (FS: $2.53 \pm 0.76 \mathrm{~mm} ; \mathrm{FV}: 1.93 \pm 0.46 \mathrm{~mm}$ ), external diameter (FS: $2.50 \pm 0.74$ $\mathrm{mm} ; \mathrm{FV}: 2.81 \pm 1.53 \mathrm{~mm}$ ) and distance to the FO (FS: $3.45 \pm 1.29 \mathrm{~mm} ; \mathrm{FV}: 2.63 \pm 1.24 \mathrm{~mm}$ ). In light of the morphometric and morphological variations of skull-based foramina, the evaluation of the FS and FV in our study may provide a reliable osteometric reference in clinical practice which may be beneficial during interpretation of imaging and surgical intervention.

KEY WORDS: Foramen spinosum; Foramen venosum; Foramen of Vesalius; Middle cranial fossa; Greater wing of sphenoid bone.

\section{INTRODUCTION}

The greater wing of the sphenoid bone is marked by numerous foramina which transmit vital neural and vascular structures (Dogan et al., 2014). These foramina are characteristically situated along the medial aspect of the floor of the middle cranial fossa. Many variants have been described in the anatomic and radiologic literature which is not only important to understand the complex regional neurovascular anatomy but also to distinguish the normal from the potentially abnormal structures (Curtin et al., 1984; Pandolfa et al., 1987).

One such foramen is the Foramen Spinosum (FS) which is located in close proximity postero-lateral to Foramen ovale (FO) and transmits the middle meningeal vessels, the meningeal branch of mandibular nerve and the nervous spinosus (Dogan et al.; Srimani et al., 2014). The transmission of these neurovascular structures allows for communication between the middle cranial and the infratemporal fossae (Kwathai et al., 2012; Srimani et al.).

In addition, the foramen venosum (Foramen of Vesalius) (FV) is occasionally present within the greater wing of the sphenoid bone (Wood-Jones, 1931; Chaisuksunt et al., 2011). The FV is also known as the sphenoid emissary foramen, foramen venosum and canaliculus sphenoidalis and usually opens into the scaphoid fossa infero-laterally (Bergman et al., 2006; Shaik et al., 2012). Although the relatively small $\mathrm{FV}$ is unique to humans due to its inconsistency, it is generally situated antero-medial to the FO (Wood-Jones; Chaisuksunt et al.; Shaik et al.). The name of FV is derived from the structure it transmits intracranially, the small emissary vein or "Vein of Vesalius", through which the pterygoid plexus and cavernous sinus communicate in

\footnotetext{
* Department of Clinical Anatomy, College of Health Sciences, School of Laboratory Medicine \& Medical Sciences, University of KwaZulu-Natal, Durban, South Africa.
} 
the parapharyngeal space (Henderson, 1966; Gupta et al., 2005; Chaisuksunt et al.; Shaik et al.). Henderson stated that occasionally this emissary vein may be a venous sinus which exits through the anterior aspect of FO when FV is absent; thus non-visualization is a known anatomic variation. Additionally, Fisher (1913) reported entry of the meningeal branch of ascending pharyngeal artery into FV; while Lang (1983) and Gupta et al. described a small nerve, the "nervoulus sphenoidalis lateralis", passing through this foramen to the cavernous sinus.

As the FO is regarded as an easily accessible portal to the mandibular division of the trigeminal nerve during percutaneous trigeminal rhizotomy and neural blockade anesthesia, the proximity of the FS to the FO may render the middle meningeal vessels vulnerable to iatrogenic injury, thereby increasing the risk of extradural hematomas (Shaik et al.; Srimani et al.). Since the emissary vein connects the intracranial venous sinuses with the extracranial veins, the FV presents a passage along which a diseased thrombus may pass from the exterior into the interior of the cranium (Gupta et al.; Chaisuksunt et al.; Shaik et al.). The FV is also considered to be one of the most pathologically affected foramina as tumors of nasopharyngeal origin often tend to invade the middle portion of the skull base (Lanzieri et al., 1988).

In view of the surgical and anesthetic explorative maneuvers involving the skull-base, an accurate osteometric evaluation of the FS and FV including their relative incidences, shapes, morphometric details, respective relations to the $\mathrm{FO}$ and/or presence of any anomalies bears much significance. Therefore, this study aimed to document the morphology and morphometry of the FS and FV.

\section{MATERIAL AND METHOD}

Osteometric investigations were performed on 100 randomly selected dry human skulls which were obtained from the existing osteological bank at the Department of Clinical Anatomy, University of KwaZulu-Natal. Metric as well as non-metric parameters were analyzed and a database was created $(n=200)$. A total of 213 foramina were identified (106 right, 107 left). Measurements were recorded with a digital caliper (Wilson Wolpert 110-15DAB, Netherlands). The shape, mean width, distance of FV and its relation to FO were calculated as a percentage of the total number of foramina on each side. Statistical analysis was conducted using a paired T-Test and significant parameters were values whose reality level was $\leq 0.05$. These results were compared with those available in the literature.

\section{RESULTS}

All foramina were described as separate entities. There was no confluence of FS with FV or FO or vice versa. No statistically significant differences between sides were observed.

Morphological features of the FS and FV were recorded as follows:

i) Incidence (n= 200): single (FS: 95\%; FV: 5\%); duplicate (FS: $2.5 \%$; FV: 0\%); triplicate (FS: 0.5\%; FV: $0 \%$ ); absent (FS: 2\%; FV: 0\%) (Figs. 1-4, Table I);

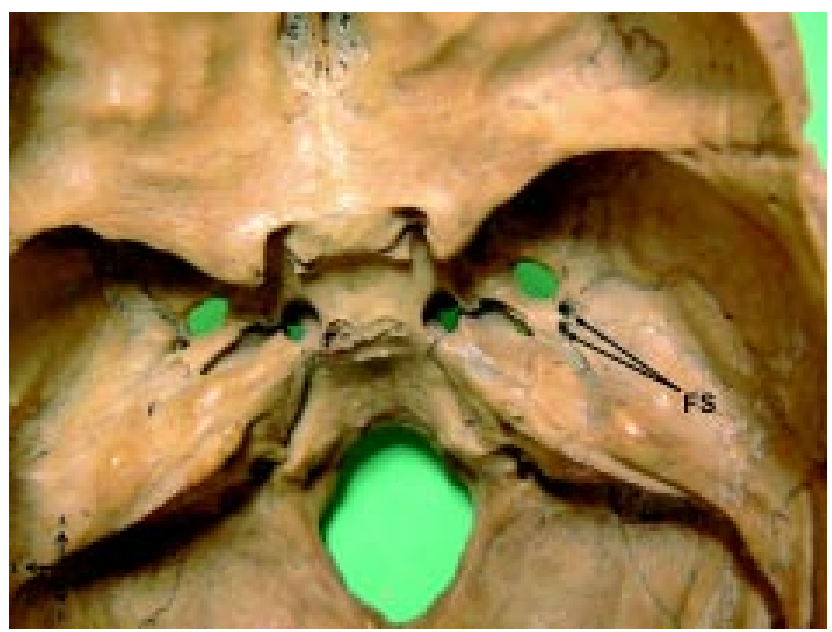

Fig. 1. Superior view of middle cranial fossa demonstrating duplicate FS. Key: A= Anterior; FS= Foramen spinosum; L= Lateral; $\mathrm{M}=$ Medial; $\mathrm{P}=$ Posterior.

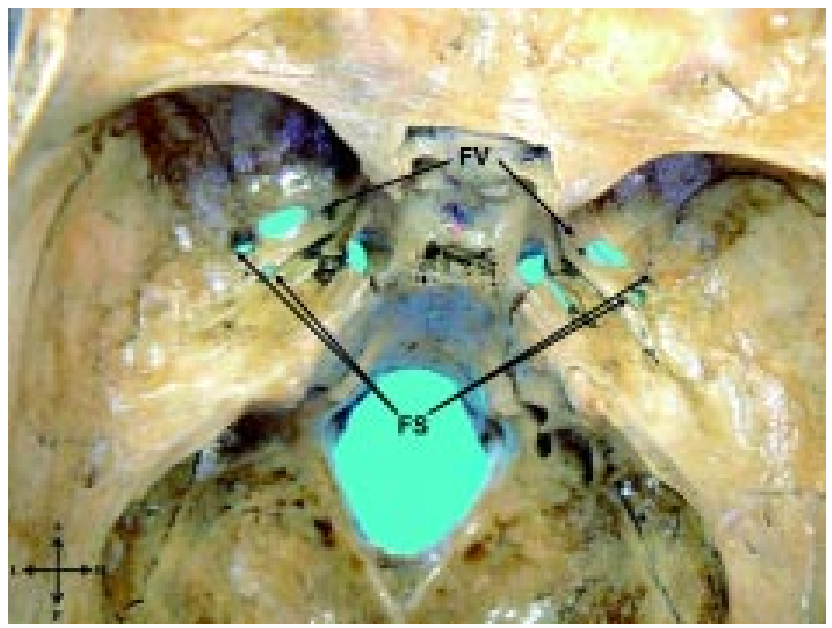

Fig. 2. Superior view of middle cranial fossa demonstrating duplicate FS and single FV bilaterally. Key: A= Anterior; FS= Foramen spinosum; FV= Foramen Venosum; L= Lateral; $\mathrm{M}=$ Medial; $\mathrm{P}=$ Posterior. 


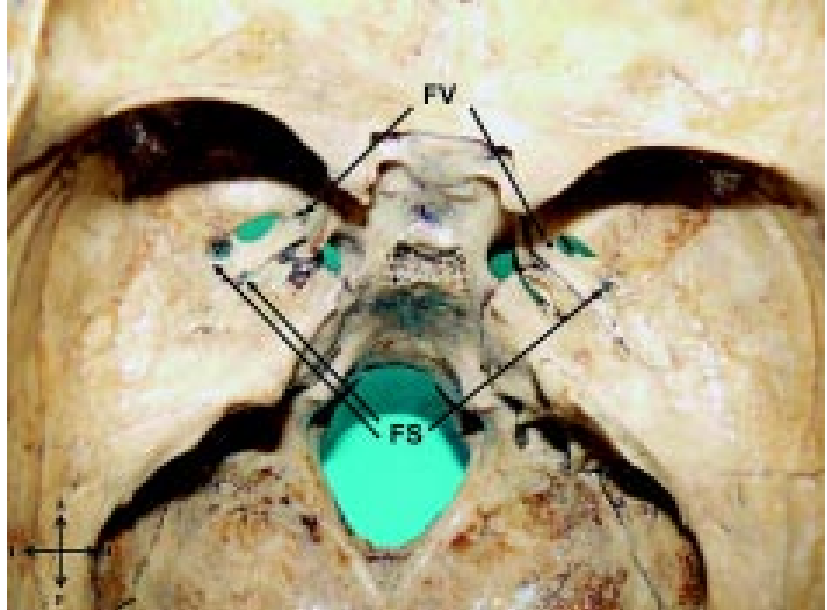

Fig. 3. Superior view of middle cranial fossa demonstrating duplicate FS and single FV on the left side and single FS and FV on the right side. Key: $\mathrm{A}=$ Anterior; $\mathrm{FS}=$ Foramen spinosum; FV= Foramen Venosum; L= Lateral; $\mathrm{M}=$ Medial; $\mathrm{P}=$ Posterior.

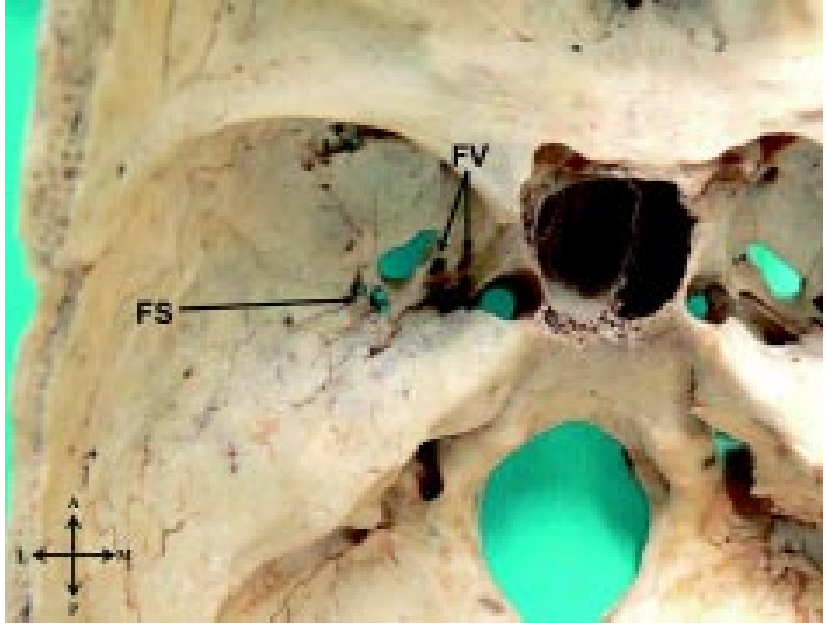

Fig. 4. Superior view of the middle cranial fossa demonstrating triplicate FS and duplicate FV on the left side. Key: A= Anterior; $\mathrm{FS}=$ Foramen spinosum; FV= Foramen Venosum; L= Lateral; $\mathrm{M}=$ Medial; $\mathrm{P}=$ Posterior.

Table I. Morphology and morphometry of FS and FV.

\begin{tabular}{|c|c|c|c|c|c|c|}
\hline \multirow{2}{*}{$\begin{array}{l}\text { Parameter } \\
\text { Incidence }\end{array}$} & \multicolumn{3}{|c|}{ Foramen Spinosum } & \multicolumn{3}{|c|}{ Foramen Venosum } \\
\hline & $\mathbf{R}(\mathbf{n}=\mathbf{1 0 0})$ & $L(n=100)$ & Total $(n=200)$ & $R(n=100)$ & $\mathbf{L}(\mathbf{n}=\mathbf{1 0 0})$ & Total $(n=200)$ \\
\hline Single & $95(95 \%)$ & $95(95 \%)$ & $190(95 \%)$ & $5(5 \%)$ & $5(5 \%)$ & $10(5 \%)$ \\
\hline Duplicate & $3(3 \%)$ & $2(2 \%)$ & $5(2.5 \%)$ & --- & $1(1 \%)$ & $1(0.5 \%)$ \\
\hline Triplicate & --- & $1(1 \%)$ & $1(0.5 \%)$ & --- & --- & --- \\
\hline Absent & $2(2 \%)$ & $2(2 \%)$ & $4(2 \%)$ & --- & --- & --- \\
\hline *Shape & $R(n=106)$ & $L(n=107)$ & Total $(n=213)$ & $R(n=106)$ & $L(n=107)$ & Total $(n=213)$ \\
\hline Oval & $39(36.8 \%)$ & $48(44.9 \%)$ & $87(43.5 \%)$ & $4(3.8 \%)$ & $5(4.7 \%)$ & $9(4.5 \%)$ \\
\hline Round & $62(58.5 \%)$ & $54(50.5 \%)$ & $116(58 \%)$ & $1(0.9 \%)$ & --- & $1(0.5 \%)$ \\
\hline \multicolumn{7}{|l|}{ *Mean diameter $(\mathbf{m m})$} \\
\hline Internal & $2.47 \pm 0.73$ & $2.59 \pm 0.78$ & $2.53 \pm 0.76$ & $2.06 \pm 0.19$ & $1.79 \pm 0.73$ & $1.93 \pm 0.46$ \\
\hline External & $2.46 \pm 0.72$ & $2.54 \pm 0.76$ & $2.50 \pm 0.74$ & $2.83 \pm 1.65$ & $2.79 \pm 1.40$ & $2.81 \pm 1.53$ \\
\hline *Distance to FO $(\mathrm{mm})$ & $3.44 \pm 1.32$ & $3.46 \pm 1.26$ & $3.45 \pm 1.29$ & $2.83 \pm 1.59$ & $2.42 \pm 0.88$ & $2.63 \pm 1.24$ \\
\hline \multicolumn{7}{|l|}{ *Relation to FO } \\
\hline Postero-lateral & $99(93.4 \%)$ & $99(92.5 \%)$ & $198(93 \%)$ & --- & --- & --- \\
\hline Posterior & $2(1.9 \%)$ & $2(1.9 \%)$ & $4(1.9 \%)$ & --- & --- & --- \\
\hline Postero-medial & --- & $1(0.9 \%)$ & $1(0.5 \%)$ & --- & --- & --- \\
\hline Anterior & --- & --- & --- & $1(0.9 \%)$ & --- & $1(0.5 \%)$ \\
\hline Antero-medial & --- & --- & --- & $4(3.8 \%)$ & $5(4.7 \%)$ & $9(4.5 \%)$ \\
\hline
\end{tabular}

* Shape, Mean length, distance and relation to FO were calculated as a percentage of the total number of foramina on each side

ii) Shape (n=213): oval (FS: 43.5\%; FV: $4.5 \%)$; round (FS: 58\%; FV: $0.5 \%$ ) (Table I);

iii) Relation to FO: postero-lateral (FS: 93\%; FV: 0\%); posterior (FS: $1.9 \%$; FV: 0\%); postero-medial (FS: 0.5\%; FV: $0 \%$ ); anterior (FS: 0\%; FV: 0.5\%); antero-medial (FS: 0\%; FV: $4.5 \%$ ) (Table I).

Mean morphometric parameters pertaining to the FS and FV and their relation to FO were documented: i) Internal diameter (FS: $2.53 \pm 0.76 \mathrm{~mm}$; FV: $1.93 \pm 0.46 \mathrm{~mm}$ ) (Table I);

ii) External diameter (FS: $2.50 \pm 0.74 \mathrm{~mm}$; FV: $2.81 \pm 1.53$ mm) (Table I);

iii) Distance to FO (FS: $3.45 \pm 1.29$ mm; FV: $2.63 \pm 1.24 \mathrm{~mm}$ ) (Table I). 


\section{DISCUSSION}

The FS is typically located postero-lateral to FO (93\% in this study), along the posteromedial aspect of the greater wing of the sphenoid bone and is usually round or oval in shape (Ginsberg et al., 1994). This study also describes posterior and postero-medial locations of the FS in relation to the FO (Table I).

The FS was absent in $2 \%$ of cases in our study (Tables I and II). It is postulated that in the absence of a FS, the middle meningeal artery enters the cranial cavity through the FO (Reymond et al., 2005). Ginsberg et al. provide an additional explanation of the absence of a FS in the case of an aberrant middle meningeal artery which arises from the stapedial branch of the internal carotid artery or the ophthalmic artery (Lindblom, 1936; Paullus, 1977). Fisher (1914) and Greig (1929) have explained the embryologic development of the middle meningeal artery. The stapedial artery originates as a dorsal branch of the second aortic arch and is part of the carotid arterial system (Fisher; Greig). In the $15 \mathrm{~mm}$ embryo, the infraorbital and mandibular branches of the stapedial artery fuse with the external carotid artery and are destined to become the internal maxillary artery (Fisher; Greig). The main trunk of the stapedial artery atrophies and its origin from the internal carotid disappears (Fisher; Greig). The usual distribution of the stapedial artery is then replaced by branches from the external carotid artery (Fisher; Greig). If the connection with the external carotid artery fails to occur, the superior or supraorbital branch of the ophthalmic artery becomes the middle meningeal artery (Fisher; Greig). In this case the middle meningeal artery enters the skull through the superior orbital fissure. Lindblom reported this variation in $0.4 \%$ of cases. However, the stapedial artery may also persist. This vessel has also been associated with an aberrant internal carotid artery. The persistent stapedial artery courses through the tympanic cavity, between the crura of the stapes and enters the facial canal distal to the geniculate ganglion. It enters the middle cranial fossa by the facial hiatus and becomes the middle meningeal artery. In both of these cases of a variant middle meningeal artery, the FS will be tiny or absent (Ginsberg et al.).
Table II. Incidence and shape of foramina spinosum and venosum in a review of literature.

\begin{tabular}{|c|c|c|c|}
\hline \multirow[t]{2}{*}{ Author (year) } & \multirow[t]{2}{*}{ Sample size } & \multicolumn{2}{|c|}{ Incidence (\%) } \\
\hline & & Spinosum & Venosum \\
\hline \multicolumn{4}{|l|}{ Incidence: Absent } \\
\hline Lindblom (1936) & Not recorded & 0.4 & --- \\
\hline Berlis et al. (1992) & 60 & 0.8 & 64.0 \\
\hline Ginsberg et al. (1994) & 123 & 3.2 & 20.3 \\
\hline Kim et al. (1997) & 163 & 2.5 & 45.4 \\
\hline Sharma \& Garud (2011) & 50 & --- & 38.0 \\
\hline Chaisuksunt et al. (2012) & 754 & --- & 89.1 \\
\hline Present study & 200 & 2.0 & --- \\
\hline \multicolumn{4}{|l|}{ Incidence: Single } \\
\hline Sondheimer (1971) & 50 & --- & $15 \%$ \\
\hline Lang (1983) & Not recorded & --- & 40.0 \\
\hline Lanzieri et al. (1988) & 54 & --- & 72.2 \\
\hline Ginsberg et al. (1994) & 123 & 48 & 80.0 \\
\hline Kim \& Kim (1995) & 305 & --- & 47.5 \\
\hline Kim et al. (1997) & 163 & --- & 51.5 \\
\hline Kodama et al. (1997) & 400 & --- & 21.8 \\
\hline Teul et al. (2002) & 187 & 100 & --- \\
\hline Gupta et al. $(2005)^{\mathrm{a}}$ & 35 & --- & 42.9 \\
\hline Reymond et al. (2005) & 100 & 100 & 17.0 \\
\hline Sharma \& Garud (2011) & 50 & 100.0 & 62.0 \\
\hline Chaisuksunt et al. (2012) & 754 & --- & 10.9 \\
\hline Kwathai et al. (2012) & 206 & 52.4 & --- \\
\hline Shaik et al. (2012) & 250 & --- & 36.0 \\
\hline Dogan et al. (2014) & 62 & --- & 32.3 \\
\hline Ozer \& Govsa (2014) & 344 & --- & 34.8 \\
\hline Srimani et al. (2014) & 80 & --- & 5.0 \\
\hline Present study & 200 & 95.0 & 5 \\
\hline \multicolumn{4}{|l|}{ Incidence: Duplicate } \\
\hline Ginsberg et al. (1994) & 123 & 0.8 & 13.8 \\
\hline Kim et al. (1997) & 163 & --- & 3.1 \\
\hline Ozer \& Govsa (2014) & 344 & --- & 0.6 \\
\hline Present study & 200 & 2.5 & 0.5 \\
\hline \multicolumn{4}{|l|}{ Incidence: Triplicate } \\
\hline Present study & 200 & 0.5 & --- \\
\hline \multicolumn{4}{|l|}{ Shape: Oval } \\
\hline Kwathai et al. (2012) & 206 & 39.3 & --- \\
\hline Srimani et al. (2014) & 80 & 30 & --- \\
\hline Lazarus et a l. (2014) & 213 & 43.5 & 4.5 \\
\hline \multicolumn{4}{|l|}{ Shape: Round } \\
\hline Kwathai et al. (2012) & 26 & 43.2 & --- \\
\hline Srimani et al. (2014) & 80 & 51.3 & --- \\
\hline Present study & 213 & 58 & 0.5 \\
\hline
\end{tabular}

In this study single FS appeared in $95 \%$ of cases which corroborated the findings of previous studies (Table II). Duplicate FS were observed in $2.5 \%$ of cases vs. $0.8 \%$ recorded by Ginsberg et al. (Table II). Duplication can be explained by early division of the middle meningeal artery into a posterior and anterior division resulting in a duplicate FS (Lindblom; Sondheimer, 1971; Reymond et al.). The literature reviewed remains silent on the course of the meningeal branch of the mandibular nerve in the absence or duplication of a FS. 
FS was observed at a distance of $3.45 \pm 1.29 \mathrm{~mm}$ to FO which compared favorably to that reported by Paullus $e t$ al. and Aslan et al. (1998) (Table III).

Table III. Distance of foramen spinosum to foramen ovale in a review of literature.

\begin{tabular}{lcc}
\hline Author (year) & Distance $(\mathbf{m m})$ & Range $(\mathbf{m m})$ \\
\hline Paullus et al. $(1977)$ & 3.2 & $1.0-6.0$ \\
Aslan et al. $(1998)$ & 3.7 & $2.0-11.0$ \\
Present study & $\mathbf{3 . 5}$ & $\mathbf{0 . 9 - 8 . 6}$ \\
\hline
\end{tabular}

The internal and external diameters of FS varied from side to side but did not usually exceed $3 \mathrm{~mm}$ (Table I). Table IV describes diameters of FS culled from the literature. According to Sondheimer, in the instance of the diameter exceeding $5 \mathrm{~mm}$, the patient should be immediately evaluated for middle meningeal artery abnormality.

The FV is regarded as a small opening in the medial aspect of the greater wing of the sphenoid bone antero-medial to FO. In this study FV was located anterior $(0.5 \%)$ or anteromedial $(4.5 \%)$ to FO (Table I). Single (5\%) and duplicate $(0.5 \%) \mathrm{FV}$ were observed which correlated with the wide range in incidence of this foramen reported in the literature reviewed $(0.6-80 \%)$ (Table II). In the absence of the FV, the respective emissary vein leaves the skull through the FO (Henderson). It is also postulated that the emissary vein is a dural venous sinus rather than a vein (Henderson). In addition, Lang and Gupta et al. described a small nerve, the nervoulus sphenoidalis lateralis, which may also pass through the FV into the cavernous sinus.

The FV was identified to be situated $2.63 \pm 1.24 \mathrm{~mm}$ from the FO, a finding which may be regarded as a unique reference measurement as it has not been reported in previous literature. The internal and external diameters were found

Table IV. Diameter of foramina spinosum and venosum in a review of literature.

\begin{tabular}{lcc}
\hline Author (year) & $\begin{array}{c}\text { F. Spinosum } \\
(\mathbf{m m})\end{array}$ & $\begin{array}{c}\text { F. Venosu m } \\
(\mathbf{m m})\end{array}$ \\
\hline Sondheimer $(1971)$ & $1.50-3.0$ & --- \\
Lang et al. $(1984)$ & 2.1 & 1.1 \\
Yanagi $(1987)$ & 2.7 & --- \\
Berlis et al. $(1992)$ & 1.9 & 1.0 \\
As lan et al. $(1998)$ & --- & --- \\
Sharma \& Garud (2011) & 2.6 & --- \\
Chai suksunt et al. $(2012)$ & --- & $1.5 \pm 0.7$ \\
Kwathai et al. $(2012)$ & 2.2 & --- \\
Dogan et al. (2014) & $1.9 \pm 0.4$ & $1.3 \pm 0.5$ \\
Ozer \& Govsa $(2014)$ & --- & $0.9 \pm 0.3$ \\
Srimani et al. (2014) & --- & --- \\
Present study & $\mathbf{2 . 5}$ & $\mathbf{2 . 4}$ \\
\hline
\end{tabular}

to be $1.93 \pm 0.46 \mathrm{~mm}$ and $2.81 \pm 1.53 \mathrm{~mm}$, respectively, which were markedly increased in comparison with the values recorded in earlier studies (Table IV). Ozer \& Govsa (2014) explained that the FV presenting with a diameter of less than $0.5 \mathrm{~mm}$ are most reliable and safe during percutaneous practice as apertures of greater than $0.5 \mathrm{~mm}$ pose a major risk on the adjacent FO.

Many authors have claimed that the variations observed in skull-based foramina may be a result of the evolutionary process such that the incidence of a specific previously-observed variant may later be considered to be the variant-normal or constant of a particular geographical population and/or ethnic group (Sharma \& Garud, 2011).

\section{CONCLUSION}

In this study the evaluation of the FS and FV and their respective relationships to FO may provide a reliable osteometric standardization of the alisphenoid structures in the middle cranial fossa. The recognition and knowledge of the normal and abnormal foramen anatomy may assist in misinterpretation during various imaging procedures. As a connecting passage, the significance of the FV lies in thorough surgical intervention to prevent puncture of the trigeminal cave and cavernous sinus as well as subsequent hemorrhage of the temporal lobe. Therefore, the above information may serve as a guideline to surgeons, radiologists and anesthetists.

LAZARUS, L.; NAIDOO, N. \& SATYAPAL, K. S. Una evaluación osteométrica de los forámenes espinoso y venoso. Int. J. Morphol., 33(2):452-458, 2015.

RESUMEN: El foramen espinoso (FE) y foramen venoso (FV) son aberturas situadas en el centro de la fosa craneal media en las proximidades de un foramen oval permeable (FO). El FE y FV proporcionan el acceso a importantes estructuras neurovasculares. Un conocimiento preciso de los datos morfométricos del FE y FV, incluyendo su forma, incidencia, relación con otros forámenes o presencia de cualquier anomalía puede representar un punto de referencia anatómica fiable durante las maniobras exploratorias quirúrgicas. El objetivo de este estudio fue investigar las características morfológicas y morfométricas del FE y FV. El estudio se realizó sobre 100 cráneos humanos secos $(n=200)$ obtenidos del banco osteológico de la Universidad de KwaZulu-Natal, para producir una base de datos que pueda servir como guía útil para los cirujanos y anestesistas. Se identificaron FE únicos $(95 \%)$, dobles $(2,5 \%)$ y triples $(0,5 \%)$; junto a FV úni$\cos (5 \%)$ y dobles $(0,5 \%)$. Según forma, se encontraron forámenes de tipo oval (FE: $43,5 \%$; FV: 4,5\%) y circular (FE: $58 \%$; FV: 0,5\%). Además, se registró la relación entre FE, FV y FO: postero-lateral 
(FE: 93\%; FV: 0\%); posterior (FE: 1,9\%; FV: 0\%); postero-medial (FE: $0,5 \%$; FV: $0 \%$ ); anterior (FE: $0 \%$; FV: $0,5 \%$ ) y antero-medial (FE: 0\%; FV: 4,5\%). Los parámetros morfométricos medios de los

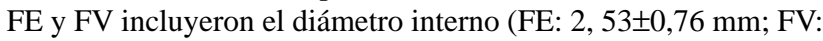
$1,93 \pm 0,46 \mathrm{~mm}$ ), diámetro externo (FS: $2,50 \pm 0,74 \mathrm{~mm}$; FV: $2,81 \pm 1,53 \mathrm{~mm}$ ) y distancia al FO (FS: $3,45 \pm 1,29 \mathrm{~mm}$; FV: $2,63 \pm 1,24 \mathrm{~mm}$ ). Considerando la morfometría y las variaciones morfológicas de los forámenes en la base del cráneo, la evaluación del FE y FV puede proporcionar una referencia osteométrica fiable en la práctica clínica, que puede ser beneficiosa durante la interpretación imagenológica y la intervención quirúrgica.

PALABRAS CLAVE: Foramen espinoso; Foramen venoso; Foramen de Vesalio; Fosa craneal media; Ala mayor del esfenoides.

\section{REFERENCES}

Aslan, A.; Balyan, F. R.; Taibah, A. \& Sanna, M. Anatomic relationships between surgical landmarks in type $\mathrm{b}$ and type $\mathrm{c}$ infratemporal fossa approaches. Eur. Arch. Otorhinolaryngol., 255(5):259-64, 1998.

Bergman, R. A.; Afifi, A. K. \& Miyauchi, R. Illustrated encyclopedia of human anatomic variation: Opus V: Skeletal systems: Cranium-Sphenoid Bone. Illustrated Encyclopedia of Human Anatomic Variation, 2006. Available from: http:// www.anatomyatlases.org/Anatomic Variants/SkeletalSystem/ Text/SphenoidBone.shtml

Berlis, A.; Putz, R. \& Schumacher, M. Direct and CT measurements of canals and foramina of the skull base. Br. J. Radiol., 65(776): 653-61, 1992.

Chaisuksunt, V.; Kwathai, L.; Namonta, K.; Rungruang, T.; Apinhasmit, W. \& Chompoopong, S. Occurrence of the foramen of Vesalius and its morphometry relevant to clinical consideration. ScientificWorld Journal, 2012: 817454, 2012.

Curtin, H. D.; Williams, R. \& Johnson, J. CT of perineural tumor extension: pterygopalatine fossa. AJNR Am. J. Roentgenol., 144(1):163-9, 1985.

Dogan, N. U.; Fazhogullari, Z.; Uysal, I. I.; Seker, M. \& Karabulut, A. K. Anatomical examination of the foramens of the middle cranial fossa. Int. J. Morphol., 32(1):43-8, 2014.

Fisher, A. G. A Case of Complete Absence of both Internal Carotid Arteries, with a Preliminary Note on the Developmental History of the Stapedial Artery. J. Anat. Physiol., 48(Pt. 1):3746,1913

Ginsberg, L. E.; Pruett, S. W.; Chen, M. Y. \& Elster, A. D. Skullbase foramina of the middle cranial fossa: reassessment of normal variation with high-resolution CT. AJNR Am. J. Roentgenol., 15(2):283-91, 1994.
Greig, D. M. Congenital anomalies of the foramen spinosum. Edinb. Med. J., 36:363-71, 1929.

Gupta, N.; Ray, B. \& Ghosh, S. Anatomic characteristics of foramen vesalius. Kathmandu Univ. Med. J. (KUMJ), 3(2):155-8, 2005.

Henderson, W. R. A note on the relationship of the human maxillary nerve to the cavernous sinus and to an emissary sinus passing through the foramen ovale. J. Anat., 100(Pt. 4):905-8, 1966.

Kim, D. I. \& Kim, H. S. High Resolution CT evaluation on the morphologic characteristics and variations of foramen ovale and adjacent foramina in the skull base. J. Korean Radiol. Soc., 33(1):43-8, 1995.

Kim, H. Y.; Chung, E. C.; Suh, J. S., Choi, H. Y.; Ko, E. J. \& Lee, M. S. Skull-Base Foramina of the Middle Cranial Fossa: Assessment of Normal Variation with High-Resolution CT. J. Korean Radiol. Soc., 36(5):747-52, 1997.

Kodama, K.; Inoue, K.; Nagashima, M.; Matsumura, G.; Watanabe, S. \& Kodama, G. Studies on the foramen vesalius in the Japanese juvenile and adult skulls. Hokkaido Igaku Zasshi, 72(6):667-74, 1997.

Kwathai, L.; Namonta, K.; Rungruang, T.; Chaisuksunt, V.; Apinhasmit, W. \& Chompoopong, S. Anatomic and morphometric consideration for external landmarks of foramen spinosum in thai dry skulls. Siriraj Med. J., 64(Suppl. 1):S26-9, 2012.

Lang, J. Clinical Anatomy of the head. Neurocranium, orbit and craniocervical region. Berlin, Springer-Verlag, 1983.

Lang, J.; Maier, R. \& Schafhauser, O. Postnatal enlargement of the foramina rotundum, ovale et spinosum and their topographical changes. Anat. Anz., 156(5):351-87, 1984.

Lanzieri, C. F.; Duchesneau, P. M.; Rosenbloom, S. A.; Smith, A. S. $\&$ Rosenbaum, A. E. The significance of asymmetry of the foramen of Vesalius. AJNR Am. J. Neuroradiol., 9(6):1201-4, 1988.

Lindblom, K. Roentgenographic study of vascular channels of skull with special reference to intracranial tumors and arteriovenous aneurysms. Acta Radiol., 30:1-146, 1936.

Ozer, M. A. \& Govsa, F. Measurement accuracy of foramen of vesalius for safe percutaneous techniques using computerassisted three-dimensional landmarks. Surg. Radiol. Anat., 36(2):147-54, 2014

Paullus, W. S.; Pait, T. G. \& Rhoton, A. L. Jr. Microsurgical exposure of the petrous portion of the carotid artery. $J$. Neurosurg., 47(5):713-26, 1977.

Pandolfo, I.; Gaeta, M.; Blandino, A. \& Longo, M. The radiology of the pterygoid canal: normal and pathologic findings. AJNR Am. J. Neuroradiol., 8(3):479-83, 1987. 
Reymond, J.; Charuta, A. \& Wysocki, J. The morphology and morphometry of the foramina of the greater wing of the human sphenoid bone. Folia Morphol. (Warsz.), 64(3):188-93, 2005.

Shaik, H. S.; Shepur, M. P.; Desai, S. D.; Thomas, S. T.; Maavishettar, G. F. \& Haseena, S. Study of foramen vesalius in South Indian skulls. Indian J. Med. Healthc., 1(1):22-4, 2012.

Sharma, N. A. \& Garud, R. S. Morphometric evaluation and a report on the aberrations of the foramina in the intermediate region of the human cranial base: A study of an Indian population. Eur. J. Anat., 15(3):140-9, 2011.

Shinohara, A. L.; de Souza Melo, C. G.; Silveira, E. M.; Lauris, J. R.; Andreo, J. C. \& de Castro Rodrigues, A. Incidence, morphology and morphometry of the foramen of Vesalius: complementary study for a safer planning and execution of the trigeminal rhizotomy technique. Surg. Radiol. Anat., 32(2):159-64, 2010

Sondheimer, F. K. Basal foramina and canals. In: Newton, T. H. \& Potts, D. G. (Eds.). Radiology of the skull and brain. St. Louis, Mosby, 1971. pp.305-21.

Srimani, P.; Mukherjee, P.; Sarkar, M.; Roy, H.; Sengupta, S. K.; Sarkar, A. N. \& Ray, K. Foramina in alisphenoid - An observational study on their osseous-morphology and morphometry. Int. J. Anat. Radiol. Surg., 3(1):1-6, 2014.

Teul, I.; Czerwin’ski, F.; Gawlikowska, A.; Konstanty-Kurkiewicz, V. \& Sawin'ski, G. Asymmetry of the ovale and spinous foramina in mediaeval and contemporary skulls in radiological examinations. Folia Morphol. (Warsz.), 61(3):147-52, 2002.

Wood-Jones, F. The Non-metrical Morphological Characters of the Skull as Criteria for Racial Diagnosis: Part I: General Discussion of the Morphological Characters Employed in Racial Diagnosis. J. Anat., 65(Pt. 2):179-95, 1931.

Yanagi, S. Developmental studies on the foramen rotundum, foramen ovale and foramen spinosum of the human sphenoid bone. Hokkaido Igaku Zasshi, 62(3):485-96, 1987.

\author{
Corresponding to: \\ Professor KS Satyapal \\ Department of Clinical Anatomy \\ College of Health Sciences \\ School of Laboratory Medicine \& Medical Sciences \\ University of KwaZulu-Natal \\ Private Bag X54001 \\ Durban \\ 4001 \\ SOUTH AFRICA
}

Telephone: + 27312607195

Email: satyapalk@ukzn.ac.za

Received: 24-06-2014

Accepted: 30-01-2015 